\title{
Creating Civil Citizens? The Value and Limits of Teaching Civility in Schools
}

\author{
Andrée-Anne Cormier $^{a}$ \& Harry Brighouse ${ }^{b}$ \\ [in C. Macleod and C. Tappolet (eds.), Philosophical Perspectives on \\ Moral and Civic Education: Shaping Citizens, London: Routledge]
}

\section{Introduction}

The US Presidential election in 2016 prompted widespread calls for enhanced civility in public life. By any standards the Republican primary, and then the general election itself, was marked by quite spectacular incivility. The ultimately successful candidate spent the primary making insulting comments about his opponents, about the looks of their wives, decrying one of his opponents widely regarded as a hero, beyond Republican ranks, as a 'loser' for having become a prisoner of war. The same candidate mimicked and made fun of a disabled reporter in a manner

a Andrée-Anne Cormier is an Assistant Professor of Philosophy at York University, Glendon Campus, in Toronto, Canada. She previously was a postdoctoral fellow in the Law Department at the Universitat Pompeu Fabra, Barcelona, working as a member of the Family Justice research project, where she worked on this paper. She received funding from the European Research Council (ERC) under the European Union's Horizon 2020 Research and Innovation programme [Grant Agreement Number: 648610].

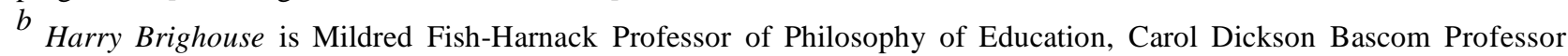
of the Humanities, Professor of Philosophy at University of Wisconsin-Madison and Director of the Center for Ethics and Education in the Wisconsin Center for Educational Research. His recent books are, with Adam Swift, Family Values: the Ethics of Parent-Child Relationships and, with Helen Ladd, Susanna Loeb and Adam Swift, Educational Goods: Values, Evidence, and Decision-making. 
that would seem juvenile in a 10-year-old. Videos emerged in which he boasted about “grabbing” women’s genitals; he slurred Mexicans as murderers, drug smugglers, and rapists, and without qualification referred to Muslims as terrorists. The Republican nominee went on to encourage crowds to call for the jailing of his opponent whom he routinely accused of being a criminal. His conduct during the televised debates verged on the bizarre, including one debate during which in full view he threateningly followed her around the stage, and memorably interrupted one of her comments by calling her a 'nasty woman'.

$62,979,636$ people voted for the candidate in question, and most senior members of his party, many of whom he had publicly insulted in crude terms (conjecturing about the size of their genitals, claiming his wife is 'hotter' than another candidate's, calling another candidate 'pathological' and comparing him with a child molester; repeatedly referring to one as "Lyin' Ted') supported his candidacy. This might not be a sign of a rise in incivility on its own, especially if the candidate in question had not become President. But it is not the only indicator. Anyone who posts a controversial opinion on the internet and gets an audience risks provoking a deluge of private and public insults and threats from those who disagree with them. Here are some examples of comments made in emails to, or placed on heavy-traffic websites about, Brighouse and his co-author Adam Swift, after their book Family Values became a minor causecélèbre among right-wing talk show and TV show hosts, who misrepresented the book, which provides a philosophical defense of the family, as being opposed to the family and, in particular, to reading bedtime stories to children (a practice which the book treats as a paradigm case of the kind of thing parents must be permitted to engage in):

You are a complete and utter dumbass. It's irresponsible idiots like you who get the rest of society campaigning against tenure for scholars in the humanities. 
Your opinion on reading to children at night might be the dumbest position ever taken on any topic in history by a free thinking human being... seriously the dumbest. Wow you're dumb.

Wow, are you a fucking idiot...er wanker. I should feel guilty because I read to my kids? Just like the typical liberal communist scum that you are, your answer for your bleeding-heart issues is to bring the rest of the world down to make others feel better about themselves. Guess what? I will read to my kids, feed them well, father the hell out them, pay for schooling and whatever else I deem proper. Your answer is to destroy the family and turn everyone in to retards. May you rot in hell.

But if true, Swift needs to be taken out back and shot.

I strongly disagree. The shooting should take place out front. ${ }^{1}$

Nobody who spends much time reading online will find this surprising. Read the comments sections of local newspapers, or even mildly controversial blogs. Over the past several years, numerous incidents on elite campuses have suggested that this incivility is not limited to politicians and blog sites; incivility towards speakers on campuses seems to be commonplace enough to warrant considerable media attention.

Some people believe we are experiencing a crisis of incivility. The Institute for Civility in Government, established long before the 2016 election in response to a perceived rise in incivility among elected officials, sponsors civility trainings, congressional student forums, and

\footnotetext{
${ }^{1}$ On file with Brighouse. Out of civility, we have chosen not to provide the names of the authors of these emails and comments which, surprisingly, they did supply to the targets of their abuse.
} 
legislative seminars, to promote what former US Congress member Jim Leach calls “A willingness to consider respectfully the views of others, with an understanding that we are all connected and rely on each other". ${ }^{2}$ The sense that there may be a crisis of incivility has led, inevitably, to concern that this will influence children which, in turn, has led to demands that schools teach civility, partly in order to counteract the effects of public political debate, and partly in order to produce a citizenry that is less susceptible to and less likely to engage in uncivil discourse, political and otherwise.

We think there are good reasons for asking schools to try and produce citizens disposed to use and practiced in civil discourse and behavior. But we also think that it is extremely difficult for schools to do so, and that those calling on schools to promote civility appropriately should be aware of these difficulties. Our chapter proceeds as follows. First, we outline what we mean by civility, drawing heavily on Cheshire Calhoun's conception. Then we give an account of the value of civility: an articulation of its potential benefits. Civility is good in many circumstances, but it is not always good. In some circumstances, it is neither morally required, nor beneficial in other ways. So, we identify what we might think of as the dark side of civility, something that must be acknowledged prior to addressing whether, and if so how, civility should be taught in schools, the question that occupies the second half of the paper. We elucidate the reasons for teaching civility in schools and what we think that doing so would involve, what demands it would make on teachers, and how the aim of promoting civility would shape the structure of schools. We conclude, though, by identifying reasons for pessimism that schools can be very successful in promoting civility: we do not think that these reasons are conclusive

\footnotetext{
${ }^{2}$ Civility Tour. At https://www.neh.gov/about/chairman/civility Accessed 6/30/2018 at 3.12PM CST
} 
against schools attempting to teach civility, but we do think that civility can only be taught if educators are clear-eyed about the hurdles they will have to overcome.

\section{What is civility?}

The notion of civility is ambiguous. In everyday discourse, it is often used interchangeably with other moral notions such as respect, tolerance, considerateness, or just politeness or good manners. When we say things like 'this person is civil' or 'this act is civil, we sometimes just mean that the person, or the act, is respectful, tolerant or considerate towards others. Given this ambiguity, it seems that a good account of civility must specify in what way (if at all) civility is distinct from, and relates to, connected moral attitudes such as the ones mentioned above. ${ }^{3}$

According to Cheshire Calhoun's thoughtful analysis ${ }^{4}$, civility is a fundamentally communicative type of moral conduct, which is irreducible, yet related, to the previous moral attitudes. The point of civility is indeed to communicate such attitudes as respect, tolerance or considerateness. It is in fact possible to be (e.g.) respectful towards others (although perhaps not fully so) without successfully communicating respectfulness to them, as when our genuinely respectful actions or beliefs towards particular others are performed in secret or simply not expressed. ${ }^{5}$ By contrast, failing to communicate respect (or other related positive moral attitudes)

\footnotetext{
${ }^{3}$ See Cheshire Calhoun, “The Virtue of Civility,” Philosophy \& Public Affairs 29, no 3 (2000): 251-275. See also Christopher F. Zurn, “Political Civility: Another illusionistic Ideal,” Public Affairs Quarterly 27, no 4 (October 2013): 341-368.

${ }^{4}$ Calhoun, “The Virtue of Civility.”

${ }^{5}$ The same goes for tolerance or considerateness.
} 
is incompatible with being civil, precisely because the moral function of civility is essentially expressive. According to this picture, then, to act civilly is to act in a way that expresses respect or tolerance or considerateness to the targets of our act. ${ }^{6}$ Thus, civility involves acting in ways that we can justifiably expect others to reasonably interpret as respectful, tolerant or considerate towards them. It involves acknowledging that there exist morally relevant facts about others that demand not only that they be treated with respect, or tolerance or considerateness, but also that messages expressing those attitudes be successfully transmitted to them, be it via speech, body language or other forms of expression. ${ }^{7}$ Crucially, this view implies that civility is tied to conformity with social rules, norms and conventions, because the latter define the meaning of our conduct. Smilingly thanking the bus driver after a ride or the waiter at a restaurant, for instance, will successfully communicate considerateness to them only because, and only insofar as, we have contingent social conventions in place specifying that so doing is considerate.

Calhoun's account has the great merit of clearly distinguishing civility from other related moral attitudes, while at the same time capturing and explaining the (intuitive) connection that exists between them as well as between civility and compliance with social norms. ${ }^{8}$ If this is the

\footnotetext{
${ }^{6}$ Correspondingly, to be a civil person, that is, a person possessing the virtue of civility, is to be genuinely disposed to communicate respect, tolerance or considerateness in our interactions with others.

${ }^{7}$ As Calhoun puts it, civil acts are “[...] acts that the target of civility might reasonably interpret as making it clear that I recognize some morally considerable fact about her that makes her worth treating with respect, considerateness, and tolerance.” (Calhoun, “The Virtue of Civility,” 259) The morally significant facts in question may include that others are persons, or more simply that they have interests, convictions and feelings of their own, which make them vulnerable to our messages, or that they are in a special relationship with us.

${ }^{8}$ Although, as we will suggest later in this paper, we think that the connection between civility and compliance with social norms is not as close or straightforward as it may seem and as Calhoun appears to believe.
} 
correct way of understanding civility, however, it appears that we have reason be somewhat suspicious of the idea that civility has significant moral value. This is so for at least two reasons, which are worth pointing out before we move on to identifying what we take the value of civility to be.

First, complying with unjust social norms is compatible with civility, and in fact might sometimes be positively required by it. For instance, it was long (and arguably in many contexts still is) viewed as considerate and even respectful of men to pay for women on romantic dates. When sufficiently robust - that is, when both parties are aware of the convention and have reason to believe that the other party is disposed to abide by the convention - the very existence of the norm renders it reasonable for men to expect women to see the gesture as considerate towards them; and for women to expect compliance with the norm. If so, civility permits, if not demands, compliance with a convention that there is good reason to believe is itself unjustly sexist. Another example seems less innocent. Denouncing sexual harassment in the workplace was long perceived, and certainly still is, in many contexts, as misplaced and somewhat inconsiderate towards (male) colleagues and employers. In such contexts, civility, considered alone, potentially recommends refraining from speaking up against sexual harassment. Incidentally, it is worth noting that social norms and conventions are also often invoked as an excuse for unacceptable behavior. Harvey Weinstein responded to the numerous serious allegations of sexual misconduct pressed against him by saying: "I came of age in the 60's and 70's, when all the rules about behavior and workplaces were different. That was the culture then."9 This highlights the possibility that sometimes the civil (or not-uncivil) thing to do is not

\footnotetext{
9 “Statement from Harvey Weinstein”, New York Times, October, 5, 2017, https://www.nytimes.com/interactive/2017/10/05/us/statement-from-harvey-weinstein.html
} 
the right thing to do - sometimes far from it. The right thing to do may involve violating, and seeking to reform, dominant social norms - including some norms compliance with which may successfully communicate positive moral attitudes to the targets of our acts. (We will come back to this last point below.)

Second, it is possible to be civil - that is, to successfully communicate tolerance or considerateness or respect - towards a person or a group that one actually denigrates or politically disrespects. For instance, one may civilly refrain from expressing homophobic beliefs in public or in front of members of the gay community, and/or successfully express positive moral attitudes to particular gay people in individual interactions, but then go about discretely campaigning against gay rights. This suggests that civility, again considered alone, is compatible with hypocrisy ${ }^{10}$ and, perhaps most importantly, that encouraging civility may present the serious moral danger of encouraging both hypocrisy and the perpetuation of injustices. ${ }^{11}$ That said, it is worth noting that some acts of compliance with social norms may easily (and reasonably) be perceived negatively as insincere or hypocritical to the targets of these acts - especially when they are insincere (e.g. motivated exclusively by strategic self-interested reasons). When this is the case, the act in question represents an unsuccessful attempt at expressing a positive moral attitude. In fact, an act of compliance with a social norm of respect or considerateness that is perceived as insincere may effectively communicate disrespect. Insincere compliance with a

\footnotetext{
${ }^{10}$ The civil act in the example above may indeed just be insincere or hypocritical. But it is worth noting that it may also (at least partly) stem from a recognition that the targets of the act have moral characteristics that makes them worthy of expressions of positive moral attitudes. The latter case seems compatible with a limited or partial form of 'genuine' respect, and does not necessarily involve hypocrisy.

${ }^{11}$ Particularly if the culture of civility is not accompanied by substantial efforts to combat injustice.
} 
social norm of respect may therefore be worse than non-compliance from the point of view of the expressive value of the act. This implies that the connection between civility and conformity to social norms is more complicated than initially thought (we say more about this in section 3).

The considerations in the previous two paragraphs not only indicate that the weight of our moral reasons to act civilly - when we have such reasons - may be quite limited, but also that educating for civility in a morally adequate way, to the extent that that can be successfully done, is a delicate matter and comes with inherent moral risks - which we will discuss in more detail in the subsequent sections. These considerations do not show, however, that civility has no moral value whatsoever, or that there are no duties of civility, or that there is no reason for schools to try and teach it to children. As we will now illustrate, we think that civility has indeed some moral value insofar as it favors the promotion of specific goods.

\section{The value of civility}

What, then, is the moral value of expressing positive moral attitudes as such? To begin with, let us note that the value of civility, as well as its moral importance, or relative moral weight, vary greatly depending on different contextual factors. This is because civility has primarily an

instrumental value ${ }^{12}$ : Civil acts generally tend to produce certain moral benefits, although they do not necessarily or always produce them.

Here is what we take to be the most significant general benefits of civility. First, civility facilitates truth-tracking dialogue by facilitating mutual learning. Second, it facilitates or

\footnotetext{
12 The value of civility may be entirely instrumental depending on how the fourth benefit we will identify is understood precisely. We leave this question aside in this paper.
} 
strengthens a sense of community, friendship and civic ties, which in turn favors solidarity and cooperation. Civility achieves these two benefits at least in part by making communication more efficient and, in particular, by reducing barriers to mutual understanding, empathy, and the development or reinforcement of a sense of connection to others. Those barriers include defensiveness, hostility, stress, anxiety, lack of trust and a sense of inferiority, all of which may be reinforced or produced by incivility (or the absence of civility). Put differently, the idea is that when we perceive other people's expressions or actions as intolerant, inconsiderate or disrespectful towards us, we are less likely, generally speaking, to listen to them, be open to learning from them, empathize with them, feel connected to them and feel part of, and willing to engage in, a common project with them, whatever it may be.

A third, related but distinct, benefit of civility is that it promotes positive emotions and feelings about each other and about oneself, including a sense of self-respect or self-esteem. It is worth distinguishing at least two types of cases in which this third benefit may occur; the second being much more morally significant: (i) when the parties are symmetrically situated with respect to power and (ii) when they are not. On the one hand, in individual interactions characterized by the absence of a power asymmetry between parties, civility can result in the individuals' experience of positive psychological states (or at least in their avoidance of negative ones). Think of a cordial exchange with a random stranger in the street, for example. On the other hand, when parties are asymmetrically situated - either due to one party belonging to a socially marginalized group or to the particular power relation that exist between the parties involved - civility can contribute to protecting the most vulnerable party from what Calhoun calls the 'emotional exhaustion' 13 of systematically facing and dealing with expressions of

\footnotetext{
${ }^{13}$ Calhoun, "The Virtue of Civility,” 266.
} 
disapproval, criticism, condemnation or hatred, which often perpetuate a perception and feeling of inferiority as well as a lack of self-esteem or sense of self-worth. This benefit of civility can be seen as more fundamental insofar as the other benefits mentioned above tend to occur when, and, at least in some cases, largely because, the third is secured. In fact, experiencing negative feelings and emotions such as a sense of inferiority or inadequacy is likely to strongly disfavor mutual learning, a sense of connection to others, cooperation, etc. Symmetrically, positive psychological states tend to favor mutual learning, a sense of connection to others, cooperation, etc. Civility thus favors the first two benefits partly via the realization of the third, so to speak. But the latter benefit remains important in its own right, since the psychological well-being of individuals, and their sense of self-worth and self-esteem, matter from a moral point of view independently of whether it produces other desirable consequences.

Finally, civility has a fourth benefit, which, in our view, is specific to civil acts directed at members of marginalized and vulnerable groups, namely, that it contributes to redressing relational inequality. ${ }^{14}$ Indeed, it is plausible to think that being in a(n unjust) relationship of inequality with fellow citizens partly involves being the systematic target of incivilities, in virtue of one's membership to a particular group. If that is true and if securing relational equality is a requirement of liberal-egalitarian justice, as we think is plausible, then the fact that the members of some groups (e.g. Muslims or African Americans) systematically face expressions of negative moral attitudes - in a word, incivilities - is part of what makes them (unjustly) marginalized. There are at least two more specific ways of understanding this idea. One may think that part of

\footnotetext{
${ }^{14}$ For discussions of relational equality, see Elizabeth Anderson “What is the Point of Equality?” Ethics, 109, No. 2 (1999): 287-337 and Carina Fourie, Fabian Schuppert, Evo Wallimann-Helmer (eds), Social Equality: On What It Means to be Equals (New York : Oxford University Press, 2015).
} 
what constitutes being (unjustly) marginalized, in particular having an (unjust) unequal social standing in society, is to be the systematic target of incivilities. Or one may think that being the systematic target of incivilities either significantly contributes to (is a source), or is an effect of, unequal standing and marginalization. Either way, expressing positive moral attitudes to the marginalized in this sense is valuable from the point of view of justice in a way that is not reducible to the potential psychological benefits of civility for the target of an act and independently of whether the act favors cooperation or mutual learning.

We want to emphasize that the moral value of civility may vary greatly according to context. Different contingent facts may affect (a) the relative moral importance of achieving any of the particular benefits of civility, as well as (b) the degree, or the magnitude, of the benefits realized by civility (if any). The overall moral value of particular civil acts (and whether there is a moral obligation to act civilly) changes accordingly. Consider (a), with respect to the benefit of favoring truth-tracking dialogue. Its moral importance seems to be higher in a learning environment such as a classroom, or an academic conference, than in an individual interaction with a fellow citizen in the street or at a grocery store. That's because learning is the primary normative aim of communication in the former case, but not necessarily in the latter. In other words, civility does not serve exactly the same function in both cases, although the overall moral importance of acting civilly might still be comparable in these contexts depending on other relevant factors. Consider now (b). It is important to notice that the benefits of civility come in degrees and that such degrees may also vary depending on several factors. A small act expressing respect towards another person in a micro-interaction may do less in the way of favoring mutual learning than does civil discourse in the classroom, but it may do more in the way of protecting the target of civility against serious cumulative emotional harm or redressing 
relational equality, e.g. if the target of the act is a member of a stigmatized group. Importantly, we think that, in virtually any context, successfully expressing positive moral attitudes to the most vulnerable, marginalized or powerless is of comparatively greater moral importance than communicating the same moral attitudes to members of less marginalized groups or less vulnerable individuals. Thus, in evaluating the moral value of acting civilly, and whether there is a duty or obligation to do so, in any particular situation, we ought to be especially sensitive to facts such as the social standing, power dynamics and vulnerabilities of the parties involved. ${ }^{15}$

Before proceeding, we want to add some important clarifications about the grounds of our duties to act civilly as well as about the relation between them and our overall moral obligations. We are not saying that what grounds our duties of civility is some kind of moral right not to be offended or to be treated by others in a way that makes us feel good. This would have implausible implications, considering that people get offended, frustrated, unhappy about

\footnotetext{
${ }^{15}$ Another factor that may affect the overall moral appropriateness of acting in a civil way in any particular situation is reciprocity. That is to say that the moral appropriateness of civil acts may, to some extent, depend on the commitment that others have to do the same. When others conduct themselves in an uncivil fashion (especially when they clearly do so in bad faith and/or persistently), remaining civil vis-à-vis them may not promote any of the goods typically associated with civility. In these cases, then, civility may not be required. Some non-civil responses to some incivilities may also send an important message of social intolerance for hateful and harmful expressions, e.g. targeting members of marginalized groups. In these circumstances, civility may even be impermissible. Having said that, it is important to notice that a reciprocal commitment to civility is not always necessary for civility to be morally good or required. Consider situations in which there is a significant power imbalance between the parties involved, such as teaching, for instance. The teacher-students relationship typically involves a power asymmetry, as well as special responsibilities on the part of the teacher. In that context, the student's lack of civility vis-à-vis the teacher, as such, is unlikely to make it permissible for the teacher conduct herself in a non-civil way vis-à-vis the student.
} 
their social interactions with others and others' speech and expressions all the time, for all kinds of reasons, including bad reasons. We also recognize that sometimes being offended and perceiving that our views are not tolerated or respected is instrumentally valuable from a moral point of view. Under some circumstances, it may 'wake us up' in valuable ways or teach us something about how to live with others despite our differences and disagreement, etc. We therefore do not think that we have an overall moral obligation to avoid offense or to 'respect' the sensitivities of others - in a word, a moral obligation to be civil - at any cost or under any circumstances. The benefits of civility must always be carefully balanced against the potential disvalue of acting civilly, and even when we do have moral duties of civilly, they may be trumped or constrained by other more important duties we have, such as denouncing injustices (even at the cost of offending some members of vulnerable minorities).

Finally, we want to be very clear about the distinction between the moral and prudential value of civility. Sure enough, some of the moral benefits of civility we have identified, especially the first two, can be prudential benefits as well (mutual learning and cooperation is typically in everyone's interest!). But the moral importance of civility remains distinct from its prudential value. It may well be the case, for instance, that the value of complying with dominant norms of civility is, for the marginalized and underprivileged, almost entirely (if not entirely) prudential - at least in many circumstances. In fact, schools teaching the Knowledge Is Power Program (KIPP) in the US teach children to be civil, but do so not because they think that in being civil the kids are fulfilling any duties, or being better people, but instead frame the benefits in terms of the prudential value for the kids of being civil. ${ }^{16}$

\footnotetext{
${ }^{16}$ See Jay Mathews, Work Hard, Be Nice. NY: Algonquin Books, 2009
} 
At the same time, civility may also not be prudent at all, perhaps especially in politics. It is not an accident that incivility is widespread in the contemporary US: We have considerable evidence that, especially in a highly polarized political environment, it can pay off. For pundits who are motivated largely by notoriety and money, incivility embeds them in a secure network of political die-hards who enjoy reinforcement of their prior assumptions. For politicians, incivility can mask lightweight or ill-considered policies. The current US President used incivility brilliantly during the primary and general election campaigns of 2016 to distract voters from his personal background, his personal inadequacies, and his limited grasp on policy matters. His opponent in the 2016 General Election was unable to wrestle the policy ground sufficiently even to win, let alone to win by the kind of margin that one might have expected. The Republican candidate, despite being an outsider to the party, deployed his incivility sufficiently well to motivate a base that was large enough and strong enough that by the time of the General Election most senior elected officials in that party felt unable openly to oppose him at all, let alone with the vigor one might have expected, given how much more profoundly most of them disagreed with him on key policy questions than they did with his opponent. In the right circumstances, incivility seems to upend truth-tracking and truth-seeking dialogue by putting people personally on the defensive or even just by bewildering them, and seems able to weaken political community and friendship across difference.

\section{The demandingness of civility}

Civility can be seriously demanding in a range of cases, much more so, in our view, than it may seem and has been acknowledged in the philosophical literature. Recall that civility, like other 
communicative acts, depends on mutual understanding of both norms and contexts. When communicators share an understanding of the context within which they are interacting, and know well the social codes in use, it can be easy for them to succeed in being civil - or uncivil. But communicative acts, like social interactions generally, are fraught with opportunities for misunderstanding. In fact, communicators often do not share a common understanding of the social norms and conventions that give particular meaning to their actions in the eyes of others.

There are at least three reasons why social norms and conventions can be quite unreliable guides for successfully communicating positive moral attitudes, or avoiding communicating negative ones, even for a well-intentioned communicator and even in cultures with the most robust norms of civility. First, many shared social norms are vague, despite being shared, and so require some degree of interpretation. And whenever there is room for interpretation, there is typically also room for reasonable disagreement. Second, different norms and conventions may co-exist at the same time within a single culture, including norms that are in tension with one another. Third, different cultures, including different institutional cultures, which co-exist within the same society or broader culture, often have their own distinct set of norms and conventions. Each of these facts creates significant opportunities for misinterpreting or misunderstanding the demands of civility. Recall indeed that civility, as we have defined it, does not (or not only) require that we carefully consider whether our acts express negative moral attitudes according to us; rather, it (also) requires that we consider how our acts may reasonably be interpreted by other people, from their own point of view. The messenger, that is to say, is not the ultimate judge of whether her message expresses (dis)respectfulness, (in)tolerance or (in)considerateness. This implies that in a range of cases, succeeding at civility, or at avoiding incivility, may necessitate not just perspective-taking and empathy, but also the possession of quite a bit of information 
about the cultural context, experiences, lives, beliefs and backgrounds of people that may be extremely different from us. In other words, some barriers to mutual understanding may need to be overcome in order to make civility possible. This may seem strange, if not paradoxical, considering that one of the moral benefits of civility itself is to reduce barriers to mutual understanding.

Sure enough, however, many acts are pretty unambiguously uncivil: they clearly express strongly negative attitudes. Some messages are explicitly hateful, offensive, and some are obviously meant to degrade and attack others. It is hard for anyone to interpret a death threat, for instance, as communicating either positive or simply neutral moral attitudes. Most of our examples in the introduction fall into this unambiguous category. Unqualifiedly referring to Mexicans as murderers, drug smugglers, and rapists, or to Muslims as terrorists, can hardly be perceived (by anyone) as respectful, tolerant or considerate towards Mexicans and Muslims. These are not difficult cases. And although these types of clear-cut incivilities are to some extent socially tolerated and quite widespread, notably in the US nowadays, there nonetheless exist in most liberal democracies, including the US, relatively robust and broadly shared social norms condemning them as incivilities. At the same time, the incivilities in question generally tend to be less strongly condemned, and regarded as less morally problematic or more morally controversial, when the targeted individuals are members of some of the most marginalized and stigmatized groups (such as Muslims).

This observation leads us to an interesting and surprising claim. It is often the case that the weightier our moral reasons to act civilly, the more significant the barriers to correctly identifying its demands, and most importantly, the less the social pressure to act civilly. In other words, the social pressure to act civilly is often higher when being civil matters less from a moral 
point of view, e.g. when there is no moral obligation to be civil. Correspondingly, it is also in many cases easier to understand what civility requires or what the civil thing to do is (which is generally a precondition to act civilly) when being civil matters less from a moral point of view. (This, of course, complicates the task of teaching civility well, as we will discuss in some detail in the following sections.) This is true in many (though far from all) cases because our most prevalent and strongest social norms and conventions are largely informed by the perspective of members of dominant groups. Many of our norms and conventions clearly specify what is required for successfully signaling respect or other positive moral attitudes to either the most powerful members of society and/or to those in position of authority. By contrast, successfully communicating positive moral attitudes to the most vulnerable and marginalized members of society might, in some cases, demand either completely violating social norms - when they are justifiably seen by those members as unjust or disrespectful towards them - or following some of the least prevalent, and most contested, social norms. Consider the case in which some level of incivility, e.g. firmly cutting off a person in the middle of her speech, is needed for inclusive purposes, e.g. to enable others to enter the conversation. A norm of civility is broken, but at the same time, respect and considerateness is likely to be successfully communicated to those invited to jump in in the conversation.

\section{What would it take to teach civility?}

For any set of knowledge, skills, dispositions and attitudes to be taught well in a school, that school must have the right aims and organizational structure, the background conditions must be reasonably cooperative, and teachers possess the relevant skills and traits. 
We'll start by sketching what should be taught. Teaching students how to be appropriately civil requires, first, that they know something about what the local civility norms are, and something about how to discover what the civility norms are wherever they might end up. Students should learn that there's both a moral and a prudential presumption in favor of abiding by the local norms of civility and, as far as possible, teach them how to abide by them through practice. This can be done through establishing prevailing norms within the school that mimic those of the surrounding society; for example, in a society in which civility norms around food include not eating before everyone is ready to eat, and not absenting oneself from the table before all have finished, a school might have different lunchtime arrangements than a society in which eating together is a less significant part of social interaction; and teachers and students might be expected to address one another with the level of formality expected in the surrounding culture. ${ }^{17}$ Students should learn that civility norms vary somewhat even within a particular society, from micro-culture to micro-culture, and learn how to exercise some humility about what civility might require in different circumstances. Students should also learn that it is normally appropriate to treat one's fellow citizens civilly in political dialogue and debate: and how to do so. ${ }^{18}$ Students should also know that when prevailing norms help to maintain a structural injustice, the moral presumption in favor of abiding by the norms is defeated; although the prudential presumption usually remains. Ideally students would learn some of the nuanced

\footnotetext{
${ }^{17}$ It is curious that in the US at least, the norms around eating at school in fact diverge radically from those that are generally expected in other settings.

${ }^{18}$ For a discussion of particular challenges teachers and schools might face in attempting this task in the current era in the US see Harry Brighouse (2018). Civic Education in the Age of Trump. On Education. Journal for Research and Debate, 1 (1). doi: 10.17899/on_ed.2018.1.2
} 
judgment required when deciding whether to act civilly when moral and prudential considerations conflict.

Now let's consider the qualities needed in the teaching force. To the extent that we want children to learn how to read, how to do basic mathematics, how to speak foreign languages, or to understand basic science, we understand that we need teachers who are, themselves, equipped with the relevant content knowledge and skills, and who have developed the necessary pedagogical skills. Equipping the teaching force with the requisite knowledge and skills is not a trivial task: even critics of traditional university-based teacher education do not think that teacher education is unimportant, just that it is poorly done in universities. Serious consideration of teaching civility in schools requires attention to the demands on the teaching force: how would teachers have to be prepared in order to teach civility?

Here are four, overlapping and interacting, qualities that a teacher needs in order to teach civility well. First, she needs a reasonably sympathetic understanding of a considerable range of political and religious stances and attitudes. Perhaps not as wide a range as the students would likely encounter outside the school, but at least as wide a range as they will encounter among the students. The reason is simple: assuming (and in section 5 we shall explain why this is a reasonable assumption at least in the contemporary US and probably in many other societies) that some fraction of her students enter the classroom with misconceptions about political, religious, or ethnic groups other than their own, and a resultant disposition to incivility, one of her tasks is going to be using classroom discussions to correct those misconceptions, something she is ill-equipped to do without herself having some understanding of the groups even if she, ultimately, deploys the diversity in the room to ensure that peers do the actual correcting of misconceptions 
Second, she needs the ability and disposition to model civility in engagement herself. This goes deep: managing a classroom of any size with students who are forced to be there is trying at the best of times. A certain severity may be compatible with inculcating mathematical skills and, maybe, physical education; but unless the teacher fairly consistently treats all her students respectfully even when they are not (yet) being respectful or civil to one another, we are skeptical that she will be consistently successful in inducing them to internalize the values needed for consistent civility.

Third, she needs the ability to guide discussions so that students can engage with each other forcefully and directly, but respectfully. Civility needs to be observed, so she needs to model it, but it also needs to be practiced, so students need to become habituated to it. It is not civil (though not necessarily uncivil) to withdraw from difference and disagreement. Civility in the classroom demands confronting difference and disagreement: expressing it but without acrimony or conveying personal hostility or criticism. A familiar experience for philosophy professors is being told by first year students that they didn't know, before taking the class, that one could argue forcefully about political or moral matters with people as one becomes friends with them: civility is one of the things they are learning.

Finally, and obviously relatedly, she needs the ability to ensure that minority as well as majority views are brought out into class discussions. This requires not just an open manner but discerning which students are holding back and why, understanding when to present the absent view oneself and when to press the student who holds it (or who, though she doesn't hold it, is willing to entertain it) to speak up - which, in turn, requires discerning to some extent which students hold which views. 
If we are right that teachers need these qualities to teach civility successfully in the secondary years, it is easy to see that it will be difficult to develop a teaching force to promote civility. These are each rare qualities: we hazard that few current social studies teachers, and few current college professors who teach controversial issues, have these qualities in anything like the degree that would optimally promote civility in their classrooms: and this despite the fact that college professors do not have the additional classroom management issues which secondary teachers typically have to deal with. Worse, these are not skills that typical teacher education programs currently have the capacity to foster: lacking the clinical faculty and having limited capacity effectively to identify and cooperate with the few teachers who already have these skills and are well-positioned to mentor others.

\section{What schools should be like}

Assume that the teaching force is well-equipped to teach civility. What demands would the school itself need to meet in order to provide a reasonably favorable environment for teaching civility?

First, think about the composition of the student body. A classroom without authentic diversity is going to be much more challenging than one in which the students genuinely have different perspectives and experiences to share. In The Political Classroom, Diana Hess and Paula McAvoy's remarkable study of secondary teachers who teach controversial issues, we encounter Mr. Kushner, who teaches at Academy High School, a public school, and Mr. Walters, 
at King High School, a private Christian school. ${ }^{19}$ The observations of their practice and interviews with students make it clear that they are both remarkable teachers: able to involve and challenge students to think better and deeper about the issues they confront. But it is also clear that the environment makes this much more difficult than it needs to be: because the classrooms both lack religious and political diversity. Mr. Walters' classroom, in a conservative Christian school, is more diverse: a couple of students come from Democrat-voting families, and there is genuine disagreement about the death penalty, but overwhelmingly the students are Christians and politically conservative. In Mr. Kushner’s classroom by contrast students are entirely from Democrat-voting families, and a poll the researchers conducted on contemporary political controversies shows no substantial disagreement: and this is not a function of selection into the class of a liberal teacher, but reflects the demographic of the school as a whole. Mr. Kushner brings in outside speakers to represent pro-life views, for example, but the absence of genuine disagreement in the classroom makes it suboptimal for fostering civil argument across disagreement.

Now think about the demands on the workforce. Students notice teachers and their attitudes to one another, and even teachers who are discrete about their own political and moral opinions often 'leak', to use Hess and McAvoy's evocative term. ${ }^{20}$ Students whose teachers express, or merely leak, contempt for Christians, or for Muslims, or for Democrats (or Socialists), or for Republicans (or Conservatives), or for opponents of abortion, or for homosexuals, or for opponents of the death penalty receive a message of incivility. A

\footnotetext{
19 Diana Hess and Paula McAvoy. The Political Classroom: Ethics and Evidence in Democratic Education. (London: Routledge, 2015), see especially chapters 6 and 7.

${ }^{20}$ Hess and McAvoy, The Political Classroom, see the discussion in chapter 9.
} 
homogenously like-minded faculty - or even just a faculty in which one set of views is sufficiently dominant that a significant number of dissenters feel they have to 'pass' - is one in which such expressions are more likely to occur regularly, and are more likely, when they do occur, to reinforce a one-sided outlook. It is not reasonable, in a society in which incivility is widespread, to expect that teachers will be immune. ${ }^{21}$ A school with a faculty and staff which is, internally, politically and religiously diverse will typically find it easier to foster civility in the students, whatever their backgrounds, than one with a homogenous faculty.

Diversity in both the student body and the teaching force is hard to achieve in the US, for the simple reason that political polarization in the US has an increasingly geographic dimension. Over the past 30 years both the Democratic and the Republican votes have concentrated, gradually, into particular counties: Congressional and state legislature seats have become ever less competitive, not only because of systematic gerrymandering, but also because increasingly Republicans and Democrats live in different cities, towns, and counties. This has an unavoidable effect on the composition of both the student bodies and the labor force: students, faculty, and other workers, are all recruited largely locally. The challenge may be less in other countries, especially those with sufficient political and religious diversity, and sufficiently dense populations. But we doubt it is an accident that the affluent democracy where the civility problem is most obviously serious has experienced this geographic separation.

Finally, think about the culture, or ethos, of the school. Schools are more likely to achieve whatever academic aims they have when the culture of the school makes manifest the valuing of those aims. A school in which teachers, principals, and other employees valorize

\footnotetext{
${ }^{21}$ It may be reasonable, even in such a society, to blame teachers for not being immune. But it is not reasonable to plan on the assumption that they will be.
} 
sporting achievement is more likely to foster engagement in sports than one in which they disdain such achievement; similarly mathematical achievement or engagement in foreign languages. While we think it likely that teaching civility requires some degree of explicit instruction, including practice in discussion of potentially divisive and controversial issues that concern the human condition, we also doubt that such instruction will be highly efficacious in a school which does manifestly value civility in its day to day operations. This does not require signs and banners reminding people to be civil (in the manner of, say, bumper stickers saying "Value Diversity"); it requires actual enactment of civil behavior among the adults in the school and in their dealings with the children in the school.

\section{Barriers to teaching civility}

No matter what, teachers and schools in some cultures - and the US is the example we will use will face considerable barriers to teaching civility. Some are built into the broader social environment, and others concern the fact that civility is not always an appropriate reaction to a situation.

The first kind of barrier concerns the lack of support for civility, especially around political and religious disagreement, in the broader social environment. Different societies have different cultures, but in the contemporary US, students will have been exposed to very limited public modeling of civility, and they have access to plenty of public modeling of incivility; and we have increasing informal evidence that incivility pays off politically. Let's start with public modeling: the past 25 years have seen the rise of highly partisan radio and television personalities who inhabit formats designed to reinforce their audiences pre-existing beliefs. The 
examples tend to be from the right. Rush Limbaugh, Anne Coulter, Glenn Beck, Bill O’Reilly, Sean Hannity, Michele Malkin: these are characters who pride themselves in being rude and offensive, in mocking and undermining, in mischaracterizing opponents and evading reasongiving. Sampling the titles of Ann Coulter's books tell an interesting story: Adios America: The Left's Plan to Turn Our Country Into a Third World Hellhole; Treason: Liberal Treachery from the Cold War to the War on Terrorism; If Democrats Had Any Brains, They'd Be Republicans; Demonic: How the Liberal Mob is Endangering America; How to Talk to a Liberal (If You Must): The World According to Ann Coulter; Mugged: Racial Demagoguery from the Seventies to Obama. Her political opponents (liberals, not socialists) are brainless, traitors, a demonic mob, who support muggers and want to turn America into a hell-hole and who (reasonably enough, if that's really what they are like) you should avoid talking to if at all possible. Sean Hannity is a less prolific writer, but his title Deliver Us from Evil: Defeating Terrorism, Despotism, and Liberalism, is supposed to carry the implicature that liberals are evil enough to warrant grouping with terrorists and despots. Former US Senator Al Franken, a liberal Democrat who was, previously, a comedian, uses similarly uncivil, if more irony-laden, titles for some of his books: Rush Limbaugh is A Big Fat Idiot, and Lies and the Lying Liars Who Tell Them.

There is some public modeling of civil dialogue, but it is rare, obscure, and by its nature not attention-grabbing. Traditionally, senior political figures would comport themselves in public with some degree of decorum; in recent times Presidents G.W. Bush and Obama, in particular, rarely raised their voices or insulted opponents, both affecting, instead, disappointment in the refusal of opponents to engage. John McCain’s concession speech after the 2008 general election and, in particular, his reaction to his audience's behavior, was a model of civility. Public television and public radio run shows in which journalists moderate discussions between pundits 
(often, themselves, journalists) of left and right who, by virtue of the rules of the format, are pleasant to one another and, sometimes, pressed to engage one another's arguments. One could use these examples in classes, and could, of course, require that students listen or watch out of class; but one could not rely on the assumption that students will encounter them, or get to know the names of the journalists involved, in the normal course of their media consumption.

The other kind of barrier to teaching civility concerns the problem that, as we argue earlier, civility is not always the proper response to a given situation. If someone is physically threatening, civility is not obligatory, and while it may be prudent, it may not be. Once you have experience of another person's persistent incivility you are entitled to disengage, or refuse to engage in the first place - not only entitled, but perhaps obliged. On the other hand, in the face of their incivility, in the presence of others who are not similarly acquainted with their character, it might be prudent and might sometimes be obligatory, to maintain the behavior that civility commends. Sometimes their behavior triggers an obligation to bystanders not to be civil. Consider a discussion conducted by two white Americans in the presence of a substantially African American audience. Use (as opposed to mention) of the word 'nigger' on the part of one of the speakers may be enough to release the other from their obligation of civility; and the presence of an audience that rightly understands itself to have been slurred by the use of the term may oblige the other to refrain from a civil response. Not only is civility not always good, it is sometimes bad, and sometimes wrong.

Compare with the simplest case: teaching basic arithmetic. The occasions when using basic arithmetic are appropriate are generally clear and do not usually require much judgment even those who struggle to compute accurately rarely have difficulty understanding when arithmetic is called for. Knowing how to identify when it is both morally permissible and 
prudentially sensible to violate the norms of civility is intrinsically difficult: and, we suspect, teaching selective compliance to teenagers whose capacities for judgment are, anyway, often impaired, is especially difficult. Not only is it difficult, but it is risky: unless done well, students may receive the message that it is up to them, as opposed to a matter of careful discerning judgment, when to be civil.

A final comment does not strictly concern a barrier to teaching civility, but a complexity. In-person civility seems to be easier for people to achieve, and maybe easier to foster in children, than at-a-distance civility. It is notable that the winner of the 2016 Presidential election, although he certainly behaved quite oddly, and rudely, was less uncivil to his opponent in the in-person debates than when talking about her when she was not present. At-a-distance incivility and, in particular, online incivility is a serious problem; and tackling it may require different strategies from tackling in-person incivility.

\section{References}

Anderson, Elizabeth. “What is the Point of Equality?” Ethics, 109, No. 2 (1999): 287-337

Brighouse, Harry. Civic Education in the Age of Trump. On Education. Journal for Research and Debate, 1 no. 1 (2018). doi: 10.17899/on_ed.2018.1.2

Brighouse, Harry, and Adam Swift. Family Values: The Ethics of Parent-Child Relationships. Princeton: Princeton University Press, 2014.

Calhoun, Cheshire. “The Virtue of Civility.” Philosophy \& Public Affairs, 29, No. 3 (2000): 251275. 
Fourie, Carina, Fabian Schuppert, and Evo Wallimann-Helmer (eds), Social Equality: On What It Means to be Equals. New York: Oxford University Press, 2015.

Hess, Diana, and Paula McAvoy. The Political Classroom: Ethics and Evidence in Democratic Education. London: Routledge, 2015.

Mathews, Jay. Work Hard, Be Nice. NY: Algonquin Books, 2009.

Zurn, Christopher F. "Political Civility: Another illusionistic Ideal.” Public Affairs Quarterly, 27, No. 4 (2013): 341-368. 